\title{
Empirical analysis of backwater level due to skewed bridge constriction
}

Kimia Haji Amou Assar MSC

Research Assistant, Department of Civil Engineering, American University of Sharjah, Sharjah, United Arab Emirates (Orcid:0000-0001-8497-6083)

\section{Serter Atabay PhD}

Professor, Department of Civil Engineering, American University of Sharjah, Sharjah, United Arab Emirates (Orcid:0000-0002-6238-3209)

(corresponding author: satabay@aus.edu)
Abdullah Gokhan Yilmaz PhD

Senior Lecturer, Department of Engineering, La Trobe University, Melbourne, Australia (Orcid:0000-0002-6813-836X)

Kazi Parvez Fattah PhD

Associate Professor, Department of Civil Engineering, American University of Sharjah, Sharjah, United Arab Emirates (Orcid:0000-0002-9620-5910)

A simple empirical method is proposed for computing the backwater level for different bridge shapes and crossings in compound channels. A series of parametric studies was conducted on the influence of the Froude number, opening ratio, discharge and roughness coefficient on the backwater depth. The results of the parametric studies, along with multiple regression analysis, were used to derive a simple accurate mathematical model for computing backwater depth. The proposed method was first compared with the energy method for different skew angles and roughness cases. Comparison of the results of the proposed method and the energy method showed good correlations. The proposed method was also validated by comparing its results with experimental data for normal and skewed crossings at $30^{\circ}$ and $45^{\circ}$. The overall absolute average percentage difference between the proposed method and the experimental data was found to be $5.1 \%$, while the overall root mean square error was found to be 0.008 .

\section{Notation}

$A_{\text {n1 }} \quad$ normal-depth cross-sectional area at the bridge $\left(\mathrm{L}^{2}\right)$

$A_{\mathrm{n} 2} \quad$ normal-depth cross-sectional area upstream $\left(\mathrm{L}^{2}\right)$

$B \quad$ channel opening width (L)

$b \quad$ width of bridge opening (L)

$b_{\mathrm{mc}} \quad$ main channel width (L)

$b_{\text {tot }} \quad$ total width of channel (L)

Fr Froude number for uniform flow in unconstricted channel

$\mathrm{Fr}_{3}$ downstream Froude number

$\mathrm{Fr}_{\mathrm{mc}} \quad$ main channel Froude number

g

$h_{3}$

$J, J_{3}$

$M$

$M^{\prime}$

$n$

$n_{\mathrm{fp}}$

$n_{\mathrm{mc}}$

$Q$

$Q_{\mathrm{fp}}$

$Q_{\mathrm{mc}}$

$Q_{\text {tot }}$

$S_{\Omega}$

$\boldsymbol{U}$

V

$Y_{1}$

$Y_{\mathrm{n}}$

$\alpha$

$\Gamma$

$\Delta h$ $\phi$

$\Omega$

\section{Introduction}

Bridges and culverts constructed across waterways disturb the water flow and result in an increase in the water level upstream of the structure. The increase in the water surface above the normal water depth before and after construction of the structure is called the backwater (Figure 1). Backwater is acknowledged to intensify the flooding of land and property upstream of the constriction, and problems associated with backwater have increased over the past decades, mainly economic disruption. It is known that backwater analysis due to bridge constrictions is not easy, especially for compound channels. The complexity of the equations and procedures of the available methods has led to many scholars developing simple mathematical methods for backwater analysis (Atabay et al., 2018; Seckin, 2004, 2007). In one of the earliest studies in the literature, Tracy and Carter (1955) proposed a numerical method for calculating the backwater depth called the 'contracted-opening' method. This method, proposed based on laboratory data from the Georgia Institute of Technology for a rectangular channel at a given discharge, implements a constricted section located downstream and an approach section with a distance equal to the width of the bridge opening upstream. Additionally, Tracy and Carter (1955) found that the water elevation downstream is influenced by downstream conditions.

In another study (Izzard, 1955), a single rectangular channel and a compound channel were compared to investigate the influence of the cross-sectional shape of the channel on the 


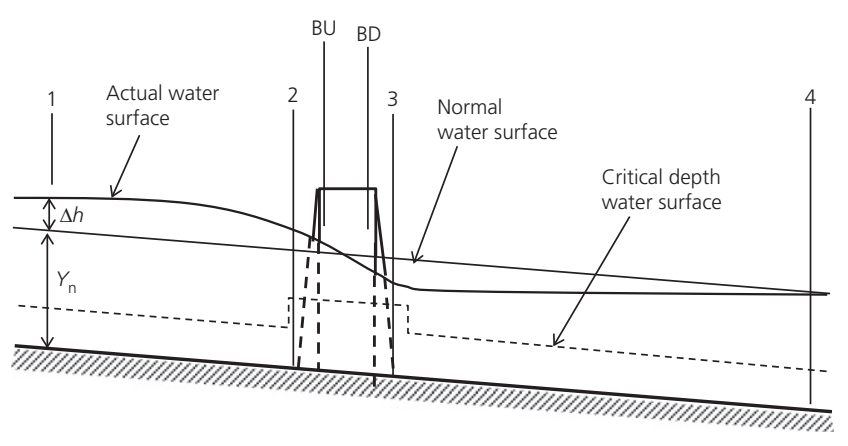

Figure 1. Water surface profile at bridges (Seckin and Atabay, 2005)

backwater level. A simplified mathematical formula for backwater level computation based on the relationship between the backwater ratio $\left(Y_{1} / Y_{\mathrm{n}}\right)$ and the Froude number (Fr) was developed:

1. $\frac{Y_{1}}{Y_{\mathrm{n}}}=1+0.45\left(\frac{\mathrm{Fr}}{M}\right)^{2}$

where $Y_{\mathrm{n}}$ is the normal flow depth of the channel with no constriction, $Y_{1}$ is the total depth at the section of maximum backwater, Fr is the Froude number for uniform flow in the channel and $M$ is the opening ratio, defined as the ratio of the bridge opening width $b$ to the channel opening width $B$.

Dimensional analysis was conducted by Liu et al. (1957) based on a physical model of a rectangular channel with an adjustable bed slope and a constriction normal to the flow. In this study, the impact of different variables on backwater levels was investigated, which resulted in the development of Equation 2 for calculating the backwater level at bridge constrictions in a prismatic channel.

2. $\left(\frac{Y_{1}}{Y_{\mathrm{n}}}\right)^{3}=4.48 \mathrm{Fr}^{2}\left[\frac{1}{M}-\frac{2}{3}(25-M)\right]+1$

However, Biery and Delleur (1962) suggested that the opening ratio defined in previous studies for rectangular bridge openings (Izzard, 1955; Liu et al., 1957) is not applicable for arch bridge openings. They thus proposed that the definition of the opening ratio should be the ratio of the normal-depth cross-sectional area of the bridge opening $\left(A_{\mathrm{n} 2}\right)$ to the normaldepth cross-sectional area of the channel $\left(A_{\mathrm{n} 1}\right)$. Furthermore, Biery and Delleur (1962) acknowledged the channel opening ratio as the factor governing the prediction of backwater levels based on studies conducted on semi-circular arch bridge constrictions. They proposed Equation 3 for backwater depth computations based on the experimental results of studies conducted by Liu et al. (1957). It should be noted that the
Froude number used in Equation 3 can be computed by Equation 4, which is for uniform flow in unconstricted channels.

3. $\frac{Y_{1}}{Y_{\mathrm{n}}}=1+0.47\left(\frac{\mathrm{Fr}}{M^{\prime}}\right)^{2.26}$

4. $\quad \operatorname{Fr}=\frac{U}{\sqrt{g\left(Y_{\mathrm{n}} / \alpha\right)}}$

where $M^{\prime}$ is the modified opening ratio, $U$ is the cross-sectional mean velocity, $\boldsymbol{g}$ is gravitational acceleration and $\alpha$ is the kinetic energy correction factor, which was assumed to be 1.0 .

Biglari and Sturm (1998) conducted a series of experimental studies in which only rectangular-opening bridges with alluvial bed forms and compound cross-sections were used. These studies led to the derivation of a two-dimensional (2D), depthaveraged $k-\varepsilon$ turbulence model for flow around bridge abutments, given in Equation 5. It should be noted that the transverse momentum, the depth-averaged continuity and the $k-\varepsilon$ turbulence equations were not considered in this study for the sake of simplicity (Biglari and Sturm, 1998).

5. $\frac{\partial(\boldsymbol{U} \Omega)}{\partial X}+\frac{\partial(\boldsymbol{V} \Omega)}{\partial Y}=\frac{\partial}{\partial X}\left[\Gamma \frac{\partial(\Omega)}{\partial X}\right]+\frac{\partial}{\partial Y}\left[\Gamma \frac{\partial(\Omega)}{\partial Y}\right]+S_{\Omega}$

where $\boldsymbol{U}$ is the longitudinal depth-averaged velocity, $\boldsymbol{V}$ is the transverse depth-averaged velocity, $\Omega$ is a generalised dependent variable, $\Gamma$ is the generalised turbulent eddy diffusivity and $S_{\Omega}$ is a generalised source term.

Based on previous experimental works, studies were conducted that focused on a compound channel with different bridge models (single semi-circular, single elliptical, straight deck bridge and multiple semi-circular models) with and without piers (Atabay and Knight, 2002; Seckin, 2004; Seckin and Atabay, 2005). For all the bridge models, Seckin (2004) concluded that the backwater level is highly dependent on the opening ratio and the Froude number. Furthermore, Seckin (2004) proposed a 1D mathematical method based on several regression analyses (Equation 6). It should be noted that this method uses the modified opening ratio $\left(M^{\prime}\right)$ proposed by Biery and Delleur (1962). This method was found to be more accurate than those proposed by Izzard (1955) and Biery and Delleur (1962), but it was suggested that the method should only be applied in predesign stages due to its level of accuracy.

6. $\frac{Y_{1}}{Y_{\mathrm{n}}}=1+0.25\left(\frac{\mathrm{Fr}}{M^{\prime}}\right)^{1.98}$ 
Seckin (2007) explored the influence of skewness on bridges and suggested a quadratic equation for backwater computation. The proposed method (Equation 7) is based on the relationship between the backwater ratio, the Froude number and opening ratio:

7a. $\frac{Y_{1}}{Y_{\mathrm{n}}}=a \mathrm{Fr}^{3}+b \mathrm{Fr}^{2}+c \mathrm{Fr}$

where

7b. $\quad a=-56.244 M^{3}+89.795 M^{2}-47.378 M+5.8345$

7c. $\quad b=62.744 M^{3}-105.420 M^{2}+53.061 M-7.3290$ skewed bridges. Again, its performance was investigated through a comparison with experimental data and it was concluded that water surface profile computed using Flow-3D was almost identical to the measured data.

Based on a series of experiments on single-opening deck and arch bridges, Atabay et al. (2018) proposed the simple mathematical formula

$$
\text { 9. } \frac{Y_{1}}{Y_{\mathrm{n}}}=0.93+\left[\frac{Q_{\mathrm{mc}}}{Q_{\mathrm{tot}}} \times \frac{b_{\mathrm{mc}}}{b_{\mathrm{tot}}}\left(\frac{\mathrm{Fr}_{\mathrm{mc}}}{M^{\prime}}\right)^{Q_{\mathrm{tot}} / Q_{\mathrm{mc}}}\right]
$$

where $\mathrm{Fr}_{\mathrm{mc}}$ is the Froude number of the main channel, $Q_{\mathrm{mc}}$ is the main channel discharge, $Q_{\text {tot }}$ is the total discharge, $b_{\mathrm{mc}}$ is the main channel width and $b_{\text {tot }}$ is the total channel width. The proposed formula was derived based on parametric studies and was validated using experimental data and the energy method. Atabay et al. (2018) found that the proposed method showed a very good correlation with the experimental data and the results obtained using the energy method. However, this method ignores the skew angle, multi-opening bridges and eccentricity, and is limited to low-flow conditions.

In addition to the simple methods proposed in the literature, several studies have addressed the computation of backwater level by implementing neural network (NN) techniques (Atabay et al., 2012; Mamak et al., 2009; Pinar et al., 2011; Seckin et al., 2009). For instance, Atabay et al. (2012)) used an artificial NN to compute the backwater depth, using Manning's roughness coefficients of the main channel and floodplain, the bridge width and the discharge. The NN model was also used to conduct a series of parametric studies (Atabay et al., 2012). However, NN techniques are usually case-by-case-based methods and consequently these techniques were not implemented in this study.

Another widely used numerical method for the analysis of open-channel hydraulics is the finite-difference method (Choi and Molinas, 1993; Fread, 1973; Islam et al., 2005; Ji, 1998; Nguyen and Kawano, 1995; Schulte and Chaudhry, 1987; Sen and Garg, 1998, 2002; Zhu et al., 2011). Zhu et al. (2011) implemented a finite-difference method to analyse and compute the flow in open-channels regardless of the flow directions for both looped and non-looped channel networks under subcritical flow conditions. The proposed method considers the backwater effects at channel junctions by means of junction-point water-stage prediction and correction (JPWSPC) instead of establishing and solving global branch equations. The JPWSPC algorithm solves for water levels and discharge iteratively in a single phase. In addition, Fayyadh et al. (2011) used finite-element modelling to investigate the structural responses of skewed bridges due to the impact of scour depth as a result of different flow velocities. The accuracy of the finite-element model was further improved by including the 
backwater flow force as a percentage of the forward flow force. Fayyadh et al. (2011) concluded that the model can be implemented for simulating water/structure correlations under low-flow conditions. Due to the iterative process of finitedifference method algorithms, the finite-difference method was not considered in the current study.

Most of the above-mentioned studies focused on computing backwater using simple mathematical methods limited to 1D and 2D models. The level of accuracy of these simple mathematical methods and their limitations in applicability indicate the necessity of developing a single comprehensive mathematical method.

Therefore, the focus of the work reported here was the acquisition of a 1D mathematical method applicable to all types of bridge shapes and crossings. It should be noted that the results of this study are limited to vertical wall abutments and subcritical flow conditions without submerging the bridge low chord or overtopping the roadway. Furthermore, eccentricity, the potential impact of piers, scour and entrance rounding were not considered in this work.

\section{Methods}

According to the literature review, the most accurate method for computing backwater depth in software packages is the energy method (Atabay, 2008; Atabay et al., 2018; Seckin, 2004). This method is available on the Hydrological Engineering Center River Analysis System (HEC-RAS) software, and so was used in this study. The following methodology was adopted to derive a simple mathematical method for computing backwater depth. First, bridge models were simulated using HEC-RAS software. The HEC-RAS bridge models were then used to conduct a series of parametric studies and the results of the parametric studies and a series of regression analyses were used to derive a mathematical model. Finally, the proposed method was evaluated using the energy method results from HEC-RAS and validated using available experimental data on compound channels.

\subsection{Computer simulation}

The HEC-RAS models were first run under low-flow conditions without bridges to obtain the normal water surface level. The models were then run with bridge models having normal and skewed crossings (Figure 2). The skewed crossings were obtained using the built-in function in HEC-RAS, which readjusts the dimensions of the bridge model for the specified skew angle to define an equivalent cross-section perpendicular to the flow (Brunner, 2010). The HEC-RAS model was embedded with cross-sections separated by a distance of $1.0 \mathrm{~m}$. Additionally, four extra cross-sections were placed, as recommended by the HEC-RAS manual (Brunner, 2010; Hunt and Brunner, 1995; Hunt et al., 1999). As shown in Figure 1, the first cross-section (labelled 1) was set upstream of the bridge at a distance equal to the bridge opening. The second

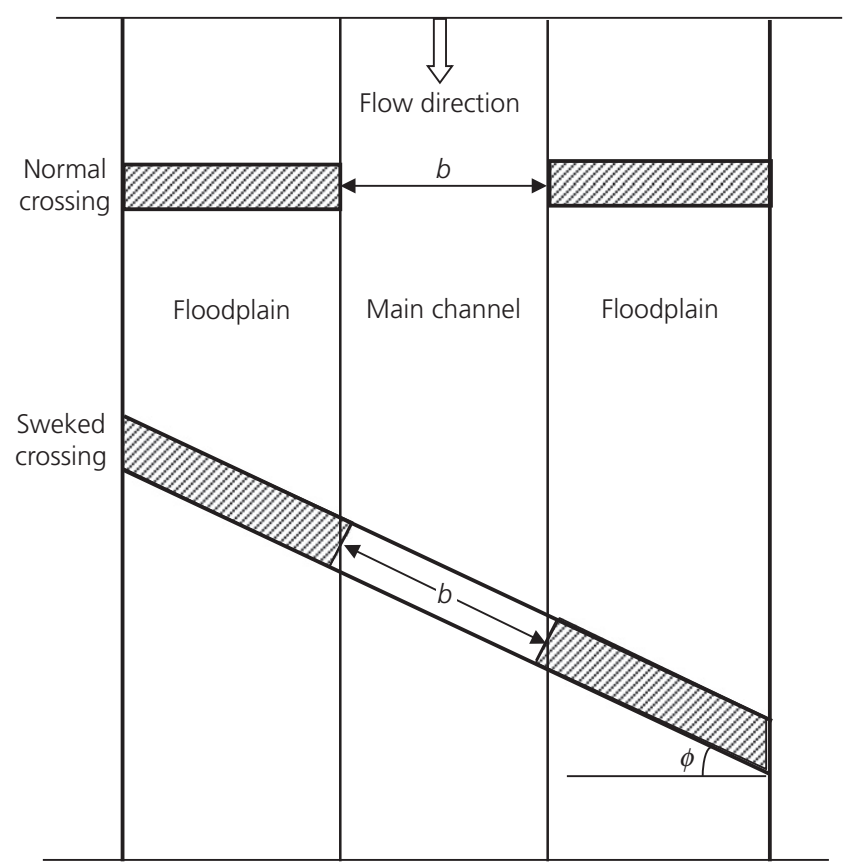

Figure 2. Illustration of different bridge crossings (adapted from Seckin (2007))

and third cross-sections (2 and 3) were placed immediately upstream of the bridge (BU) and downstream of the bridge (BD), respectively. The last cross-section (4) was placed at a distance of four times the bridge opening. The first and the last cross-sections represent the contraction and expansion lengths, with contraction and expansion coefficients substituted in the model taken as 0.3 for contraction and 0.5 for expansion.

\subsection{Parametric studies}

In a series of parametric studies, Atabay et al. (2018) indicated the influence of several factors on backwater depth, including the Froude number, the area of the main channel, the area and width of the floodplain, the main channel width and the width of the bridge opening. Atabay et al. (2018) found that the bridge opening width $(b)$ had a negative correlation with the backwater depth (i.e. an increase in $b$ results in a decrease in backwater depth). Moreover, they found positive relationships between the backwater depth and roughness coefficients and discharge values. The main channel roughness coefficients and discharge values were found to have a more significant impact on backwater depth, and similar impacts of flow rate and roughness coefficients were anticipated in the current study.

In the current work, the impacts of different factors on the backwater of skewed bridges were investigated by running different scenarios on HEC-RAS. According to Bradley (1978), for skew angles up to $20^{\circ}$, the flow pattern shows no change, but flow efficiency decreases as the skew angle 
increases above $20^{\circ}$. It is worth noting here that the implementation of projected length in HEC-RAS is not adequate for skew angles greater than $30^{\circ}$ (Bradley, 1978; Hamill, 1999). Therefore, parametric studies were performed on a deck bridge with a $398 \mathrm{~mm}$ wide opening and skew angles below $30^{\circ}$. The parametric studies included a variation in Manning's coefficients of $0.03-0.05$ for the main channel $\left(n_{\mathrm{mc}}\right)$ and $0.05-0.07$ for the floodplains $\left(n_{\mathrm{fp}}\right)$, in increments of 0.005 . In addition, the effects of different discharges on backwater depths were investigated by keeping $n_{\mathrm{mc}}$ and $n_{\mathrm{fp}}$ constant while changing the discharge $(Q)$ from $15 \mathrm{l} / \mathrm{s}$ to $35 \mathrm{l} / \mathrm{s}$ in $5 \mathrm{l} / \mathrm{s}$ increments. Table 1 shows the values used in the parametric study for all three cases, for skew angles $(\phi)$ of $0^{\circ}, 5^{\circ}, 10^{\circ}, 15^{\circ}$, $20^{\circ}, 25^{\circ}$ and $30^{\circ}$.

In the first scenario, the impact of $n_{\mathrm{mc}}$ on backwater depth was investigated by maintaining $n_{\mathrm{fp}}$ at 0.05 and $Q$ at $30 \mathrm{1} / \mathrm{s}$. As already noted, $n_{\mathrm{mc}}$ was varied from 0.03 to 0.05 in increments of 0.005 for $\phi=0-30^{\circ}$. Figure 3 represents the variation in backwater depth with the variable $n_{\mathrm{mc}}$ for each corresponding skew angle. According to Figure $3, n_{\mathrm{mc}}$ has a positive correlation with backwater depth; with an increase in $n_{\text {mc }}$, the backwater depth increases.

In the second scenario, the effect of $n_{\mathrm{fp}}$ on backwater depth was explored by maintaining $Q$ at $301 / \mathrm{s}$ and $n_{\mathrm{mc}}$ at $0.03 ; n_{\mathrm{fp}}$

Table 1. Parametric case studies

\begin{tabular}{|c|c|c|c|c|c|c|}
\hline \multicolumn{2}{|c|}{ Case 1} & \multicolumn{2}{|c|}{ Case 2} & \multicolumn{3}{|c|}{ Case 3} \\
\hline$n_{\mathrm{mc}}$ & $n_{\mathrm{fp}}$ & $n_{\mathrm{mc}}$ & $n_{\mathrm{fp}}$ & $n_{\mathrm{mc}}$ & $n_{\mathrm{fp}}$ & Q: I/s \\
\hline 0.030 & 0.050 & 0.030 & 0.050 & 0.030 & 0.050 & 15 \\
\hline 0.035 & 0.050 & 0.030 & 0.055 & 0.030 & 0.050 & 20 \\
\hline 0.040 & 0.050 & 0.030 & 0.060 & 0.030 & 0.050 & 25 \\
\hline 0.045 & 0.050 & 0.030 & 0.065 & 0.030 & 0.050 & 30 \\
\hline 0.050 & 0.050 & 0.030 & 0.070 & 0.030 & 0.050 & 35 \\
\hline
\end{tabular}

was increased from 0.05 to 0.07 in increments of 0.005 . Figure 4 shows that an increase in $n_{\mathrm{fp}}$ resulted in an increase in the backwater depth. However, $n_{\mathrm{fp}}$ was less influential than $n_{\mathrm{mc}}$ since it has a smaller positive slope.

In the last scenario, the impact of discharge $(Q)$ on backwater depth was studied by keeping $n_{\mathrm{fp}}$ and $n_{\mathrm{mc}}$ at 0.05 and 0.03 , respectively. Figure 5 shows that an increase in $Q$ led to an increase in the backwater depth. The discharge value was found to have a more significant impact on backwater depth than $n_{\mathrm{mc}}$, as the slope of the graph is steeper.

In conclusion, all the scenarios showed the anticipated results. Although all the scenarios showed a positive correlation between the skew angle and backwater depth, the impact of skew angle was not as significant as the impacts of the other three parameters $\left(n_{\mathrm{fp}}, n_{\mathrm{mc}}\right.$ and $\left.Q\right)$ as all the curves were close to each other.

\subsection{Regression analysis}

Previous studies (Atabay et al., 2018; Biery and Delleur, 1962; Izzard, 1955; Seckin, 2004, 2007; Seckin et al., 2008) also reported that the Froude number (Fr), bridge opening ratio $\left(M^{\prime}\right)$ and blockage ratio $(J)$ were also found to significantly impact backwater. Therefore, based on the parametric studies conducted, different scenarios and regression analysis, the relationship between backwater ratio and $\left(\mathrm{Fr}_{\mathrm{mc}} / M^{\prime}\right)^{J}$ for normal crossings and $30^{\circ}$ skewed crossings was investigated. As the Froude number for a compound channel requires more parameters to be considered, Fr was simplified to the main channel Froud number $\left(\mathrm{Fr}_{\mathrm{mc}}\right)$. Figure 6 shows a parabolic relationship between the backwater ratio $\left(Y_{1} / Y_{\mathrm{n}}\right)$ and $\left(\mathrm{Fr}_{\mathrm{mc}} / M^{\prime}\right)^{J}$; the coefficient of determination $\left(R^{2}\right)$ was determined to be 0.90 .

A skewed crossing usually has a smaller effective width than a normal crossing and, in addition, the geometry of arch bridges

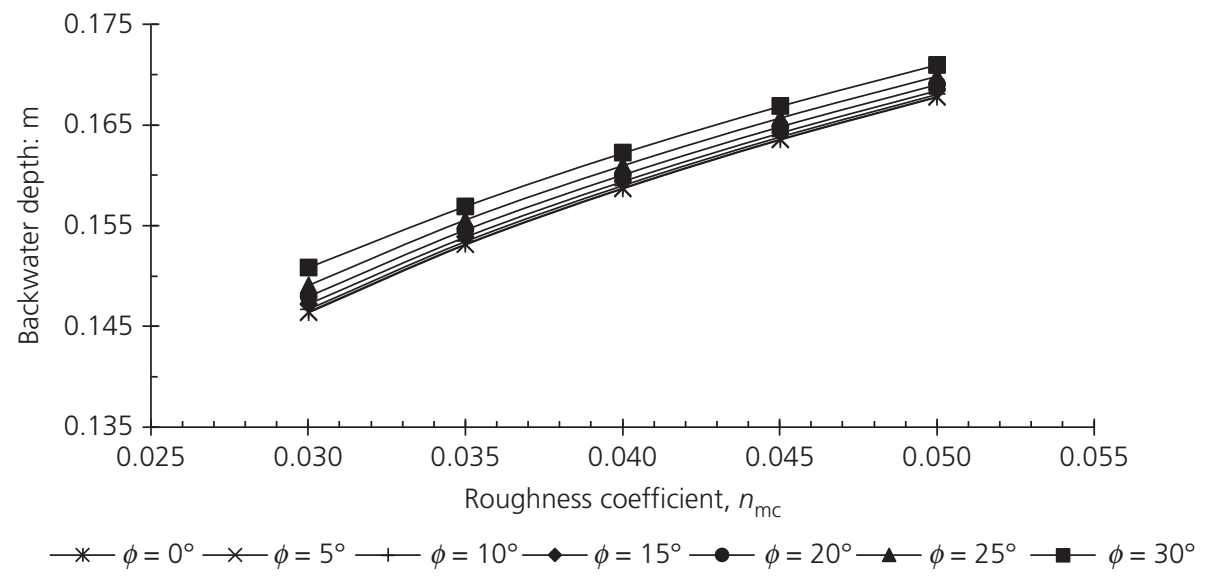

Figure 3. Variation of backwater depth with $n_{\mathrm{mc}}\left(n_{\mathrm{fp}}=0.05, Q=30 \mathrm{l} / \mathrm{s}, b=398 \mathrm{~mm}\right)$ 


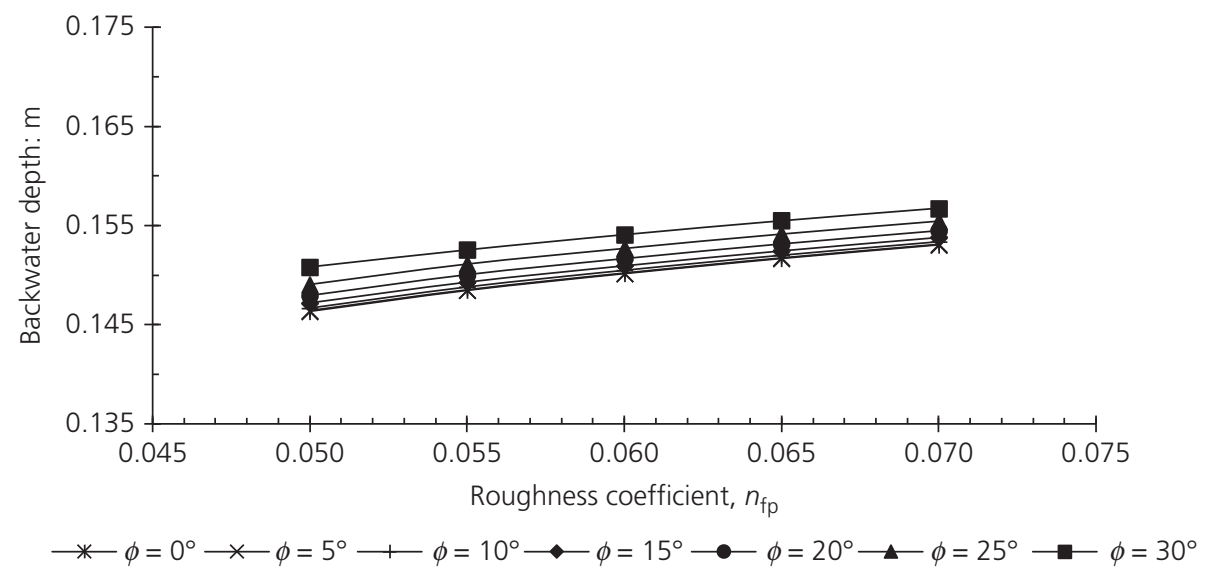

Figure 4. Variation of backwater depth with $n_{\mathrm{fp}}\left(n_{\mathrm{mc}}=0.03, Q=30 \mathrm{l} / \mathrm{s}, b=398 \mathrm{~mm}\right)$

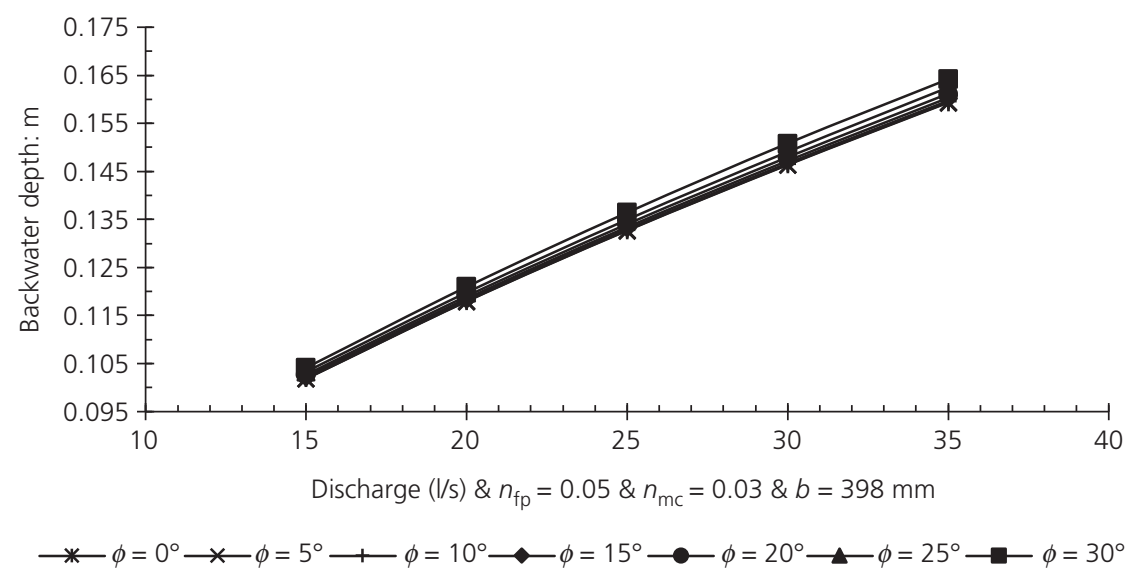

Figure 5. Backwater depth as a function of discharge

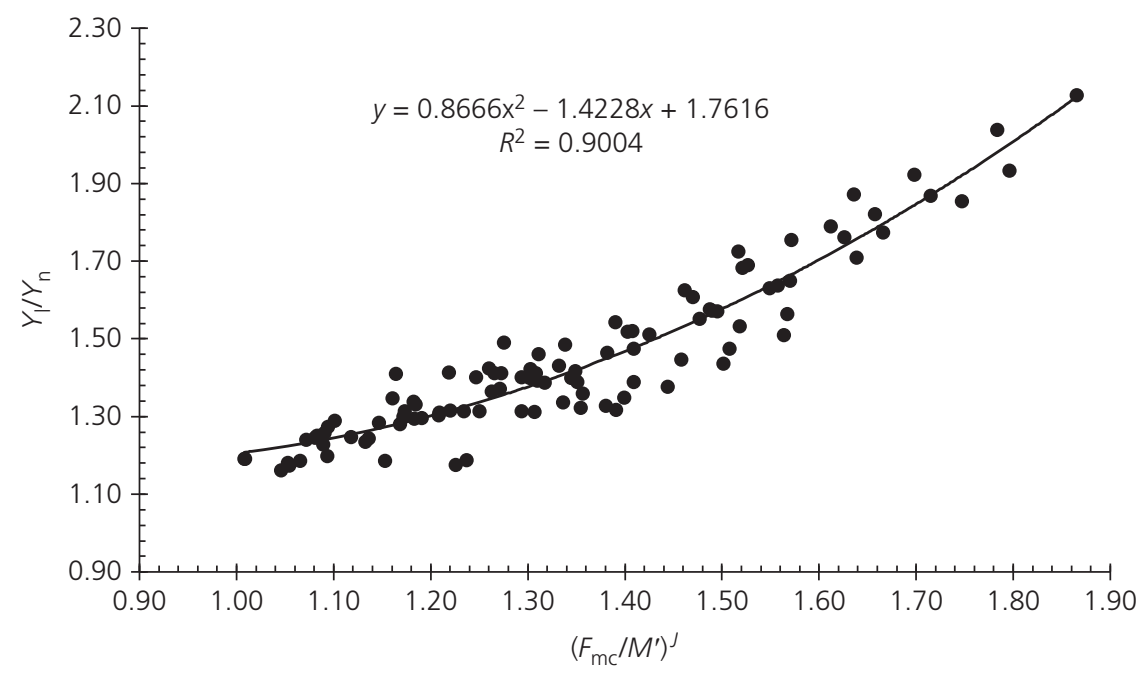

Figure 6. Regression analysis of normal and skewed bridge crossings 
when skewed is more complex than that of skewed deck bridges (Hamill, 1999; Hussain and Rao, 1966). Therefore, for skewed bridges, the opening ratio and the blockage ratio must be adjusted for the effective area normal to the flow. To adjust the opening ratio, the bridge opening width $b$ was considered to be $b^{\prime}=b \cos (\phi)$ for computing $A_{\mathrm{n} 2}$. Likewise, the projected bridge area was computed by multiplying the horizontal dimensions of the bridge by $\cos (\phi)$. The equation shown in Figure 6 was then generalised to be applicable to all types of crossings and bridge shapes using the results of the parametric studies. The proposed method is shown in Equation 10, in which a factor of 1.03 is considered to yield greater accuracy.

10. $\frac{Y_{1}}{Y_{\mathrm{n}}}=1.03 \times\left(\frac{b_{\mathrm{mc}}}{b_{\mathrm{tot}}}\left[\left(\frac{\mathrm{Fr}}{M^{\prime}}\right)^{J}\right]^{2}+\frac{b_{\mathrm{mc}}}{b_{\mathrm{tot}}} \times \frac{Q_{\mathrm{tot}}}{Q_{\mathrm{mc}}} \times\left(\frac{\mathrm{Fr}_{\mathrm{mc}}}{M^{\prime}}\right)^{J}+\frac{Q_{\mathrm{tot}}}{Q_{\mathrm{mc}}}\right)$

\subsection{Experimental data on compound channels}

A tremendous amount of experimental data on different types of bridge openings in compound channels with different roughness coefficients for the main channel and floodplains was collected by Atabay and Knight (2002) and Seckin et al. (2004) in two different phases of work at the University of Birmingham, UK. In phase 1, experiments were conducted on normal bridge crossings while, in phase 2 , experiments were conducted for skewed bridge crossings with angles of $\phi=30^{\circ}$ and $\phi=45^{\circ}$ (Figure 7). The experimental data collected in phase 1 (normal bridge crossings) have been extensively analysed in many studies (Atabay, 2008; Atabay and Knight, 2002; Seckin, 2004; Seckin and Atabay, 2005). However, the study on the skewed bridge crossings was rather limited and has not been studied in detail (Seckin et al., 2008). Therefore, the data collected for the skewed bridge crossings in phase 2 were used to validate the method proposed in this paper.

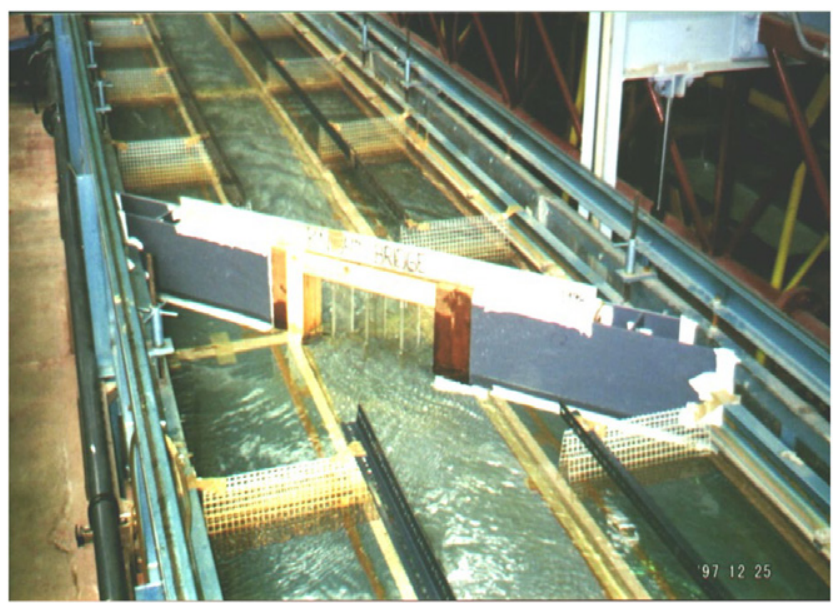

Figure 7. Experimental setup at Birmingham University, UK (Seckin et al., 2004)
Table 2. Three cases considered in phase 2 of experimental work conducted at the University of Birmingham, UK

\begin{tabular}{lcll} 
Test case & Discharge, $\mathbf{Q}: \mathbf{m}^{\mathbf{3}} / \mathbf{s}$ & \multicolumn{1}{c}{$\boldsymbol{n}_{\mathbf{f p}}$} & \multicolumn{1}{c}{$\boldsymbol{n}_{\mathbf{m c}}$} \\
\hline A & $0.018,0.040$ & 0.010 & 0.009 \\
B & $0.018,0.040$ & $0.022,0.050$ & 0.009 \\
C & $0.018,0.040$ & $0.014,0.016$ & $0.017,0.025$
\end{tabular}

Table 2 shows the different cases considered in phase 2, which were used in this study. The experimental procedure and apparatus setup have been discussed in detail elsewhere (Atabay, 2001; Atabay and Knight, 2002; Seckin, 2004, 2007; Seckin and Atabay, 2005; Seckin et al., 2008) so, for brevity, are not discussed here.

\section{Results and discussion}

As already mentioned, the energy method is acknowledged to be the most accurate method for computing backwater depth. Thus, the performance of the proposed method was evaluated by comparing its results with the energy method, considering two scenarios.

In the first scenario, due to the inadequacy of HEC-RAS for skew angles above $30^{\circ}$, the proposed method was applied for skew angles ranging from $0^{\circ}$ to $30^{\circ}$. For these analyses, the properties of case $\mathrm{A} \quad\left(n_{\mathrm{mc}}=0.009\right.$ and $\left.n_{\mathrm{fp}}=0.010\right)$ were considered. In the second scenario, the proposed method was further evaluated by considering different roughness cases using test cases A, B and C of the experimental data (Table 2) for normal crossings and $30^{\circ}$ skewed crossings. The proposed method was found to underestimate the backwater depth compared with the energy method, with percentage differences decreasing with an increase in the discharge. The overall root mean square error (RMSE) was found to be 0.007 and 0.052 for the first and second scenarios, respectively. Therefore, it was concluded that the proposed method and the energy method correlate well.

The accuracy of the proposed method was also evaluated by comparing the model results with experimental data. The proposed equation (Equation 10) was applied for each set of experimental data for both normal and skewed crossings. The average absolute percentage differences were found to be $6.5 \%$, $5.3 \%$ and $3.7 \%$ for normal, $30^{\circ}$ skewed and $45^{\circ}$ skewed bridge crossings, respectively. The overall absolute percentage difference was found to be $5.1 \%$ with an overall RMSE value of 0.008 ; the RMSE between the energy method and the experimental data was found to be 0.042 (i.e. higher than the RMSE of the proposed method). The results of these comparisons are shown in Table 3. It should be noted that the absolute differences for the energy method for $\phi=45^{\circ}$ were high. This was anticipated since the HEC-RAS manual already suggests that the energy method will not produce accurate results for angles above $30^{\circ}$. This is, of course, 
Table 3. Comparison of the proposed method and the energy method with experimental data

\begin{tabular}{|c|c|c|c|c|}
\hline \multirow{2}{*}{$\begin{array}{l}\text { Skew } \\
\text { angle, } \phi \text { : } \\
\text { degrees }\end{array}$} & \multirow[b]{2}{*}{$\begin{array}{l}\text { Number } \\
\text { of tests }\end{array}$} & & \multicolumn{2}{|c|}{ Absolute difference: \% } \\
\hline & & & $\begin{array}{c}\text { Proposed } \\
\text { method }\end{array}$ & $\begin{array}{l}\text { Energy } \\
\text { method }\end{array}$ \\
\hline \multirow[t]{3}{*}{0} & \multirow{3}{*}{48} & Maximum & 13.7 & 11.2 \\
\hline & & Minimum & 0.4 & 0.7 \\
\hline & & Average & 6.5 & 4.2 \\
\hline \multirow[t]{3}{*}{30} & \multirow[t]{3}{*}{54} & Maximum & 10.8 & 10.1 \\
\hline & & Minimum & 0.0 & 0.03 \\
\hline & & Average & 5.3 & 3.0 \\
\hline \multirow[t]{3}{*}{45} & \multirow[t]{3}{*}{54} & Maximum & 11.4 & 124.3 \\
\hline & & Minimum & 0.0 & 3.0 \\
\hline & & Average & 3.7 & 27.1 \\
\hline
\end{tabular}

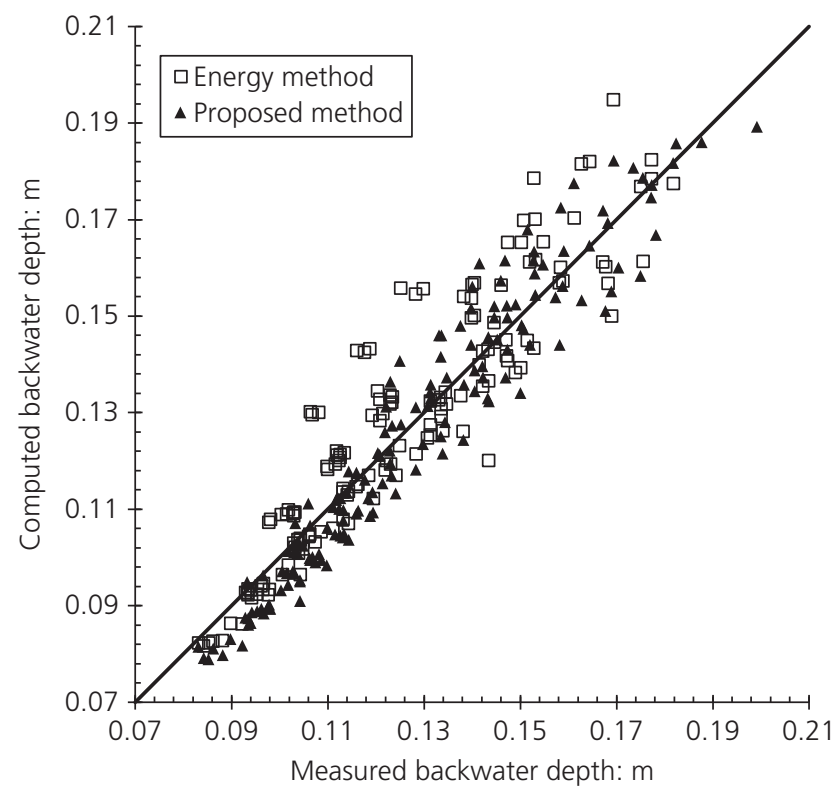

Figure 8. Comparison of measured and computed backwater depths

another reason to highlight the importance of the proposed method.

Figure 8 shows a comparison of backwater depths computed by the proposed formula and the energy method against the measured results. The proposed formula mostly underestimated the backwater depth for all types of crossings, but showed a good correlation with the experimental data. On the other hand, the energy method was found to overestimate the backwater depth in most cases. The results of the proposed method and the energy method were close, and it can thus be concluded that the proposed method can be considered to have a good correlation with the energy method, which is considered to be the most accurate method for computing backwater depth. However, the proposed method has the advantage of being simple and is applicable for skewed crossings at over $30^{\circ}$. In summary, the proposed method is a simple empirical method for computing the backwater depth for all types of crossings with a high level of accuracy and good correlations with the energy method and experimental data.

\section{Conclusions}

Different parameters that affect the backwater depth were evaluated by conducting a series of parametric studies. It was found that the main channel roughness coefficient and the discharge had the greatest impact on the backwater depth. Based on the parametric studies and multiple regression analysis, a simple mathematical method for computing the backwater depth was derived. The results of the proposed method were first compared with the energy method, considering two scenarios, and the comparison showed a good correlation. The proposed method was also validated by a comparison with experimental data reported in the literature. This comparison revealed an overall absolute average percentage difference of $5.1 \%$ with an overall RMSE of 0.008 . The HEC-RAS is inadequate for skew angles above $30^{\circ}$ (Brunner, 2010), but the proposed method has the advantage of being applicable for all skew angles even up to $45^{\circ}$. The proposed method is therefore beneficial for hydraulic engineers in any stage of designing and analysing bridges. The proposed simple mathematical method for computing backwater depth is applicable to both normal and skewed crossings of single-opening and multiple-opening bridges.

\section{Acknowledgement}

The work in this paper was supported, in part, by the Open Access Program of the American University of Sharjah. This paper represents the opinions of the authors and does not represent the position or opinions of the American University of Sharjah.

\section{REFERENCES}

Atabay S (2001) Stage-discharge, Resistance, and Sediment Transport Relationship for Flow in Straight Compound Channels. PhD thesis, University of Birmingham, Birmingham, UK.

Atabay S (2008) Accuracy of the ISIS bridge methods for prediction of afflux at high flows. Water and Environment Journal 22(1): 64-73.

Atabay S and Knight DW (2002) Bridge Afflux Experiments in Compound Channels, Phase 1. School of Civil Engineering, University of Birmingham, Birmingham, UK, Report supplied to JBA Consulting.

Atabay S, Abdalla JA, Erduran K, Mortula M and Seckin G (2012) Prediction of backwater level of bridge constriction using an artificial neural network. Proceedings of the Institution of Civil Engineers - Water Management 166(10): 556-570, https://doi.org/ 10.1680/wama.11.00112.

Atabay S, Haji Amou Assar K, Hashemi M and Dib M (2018) Prediction of the backwater level due to bridge constriction in waterways. Water and Environment Journal 23(1): 94-103.

Biery P and Delleur J (1962) Hydraulics of single span arch bridge constrictions. Journal of the Hydraulic Division 88(2): 75-108. 
Biglari B and Sturm TW (1998) Numerical modeling of flow around bridge abutments in compound channel. Journal of Hydraulic Engineering 124(2):156-164.

Bradley JN (1978) Hydraulics of Bridge Waterways: Hydraulic Design. Series no. 1, 2nd edn. US Federal Highway Administration, Washington, DC, USA.

Brunner G (2010) HEC-RAS, River Analysis System Hydraulic Reference Manual, 4.1 edn. US Army Corps of Engineers, Davis, CA, USA.

Choi GW and Molinas A (1993) Simultaneous solution algorithm for channel networks modeling. Water Resources and Reservation 29(2): 321-328.

Erduran KS, Seckin G, Kocaman S and Atabay S (2012) 3D numerical modeling of flow around skewed bridge crossing. Engineering Applications of Computational Fluid Mechanics 6(3): 475-489.

Fayyadh MM, Akib S, Othman I and Razak HA (2011) Experimental investigation and finite element modelling of the effects of flow velocities on a skewed integral bridge. Journal of Simulation Modelling Practice and Theory 19(9): 1795-1810.

Fread DL (1973) Technique for implicit dynamic routing in rivers with tributaries. Water Resources Research 9(4): 918-926.

Hamill L (1999) Bridge Hydraulics. E \& FN Spon, London, UK.

Hunt JH and Brunner GW (1995) Flow Transitions in Bridge Backwater Analysis. US Army Corps of Engineers, Davis, CA, USA, Research Document No. 42.

Hunt JH and Brunner GW and Larock BE (1999) Flow transitions in bridge backwater analysis. Journal of Hydraulic Engineering 125(9): 981-983.

Hussain ST and Rao GM (1966) Hydraulics of river flow under arch bridges. Irrigation and Power 23: 441-454.

Islam A, Raghuwanshi NS, Singh R and Sen DJ (2005) Comparison of gradually varied flow computation algorithms for open-channel network. Journal of Irrigation and Drainage Engineering 131(5): $457-465$

Izzard CF (1955) Discussions of "Backwater effects of open-channel constrictions" by H. J. Tracy and R. W. Carter. Transactions of the American Society of Civil Engineers 120: 1008-1013.

Ji Z (1998) General hydrodynamic model for sewer/channel network systems. Journal of Hydraulic Engineering 124(3): 307-315.

Kocaman S, Seckin G and Erduran KS (2010) 3D model for prediction of flow profiles around bridges. International Journal of Hydraulic Resources 48(4): 521-525.

Liu HK, Bradley JN and Plate EJ (1957) Backwater Effects of Piers and Abutments. Department of Civil Engineering, Colorado State University, Fort Collins, CO, USA, Report No. CER57HKLIO.
Mamak M, Seckin G, Cobaner M and Kisi O (2009) Bridge afflux analysis through arched bridge constrictions using artificial intelligence methods. Civil Engineering and Environmental Systems 26(3): 279-293.

Nguyen QK and Kawano H (1995) Simultaneous solution for flood routing in channel networks. Journal of Hydraulic Engineering 121(10): 744-750.

Pinar E, Secki G, Sahin B et al. (2011) ANN approaches for prediction of bridge backwater using both field and experimental data. International Journal of River Basin Management 9(1): 53-62.

Schulte AM and Chaudhry MH (1987) Gradually-varied flows in open-channel networks. Journal of Hydraulic Research 25(3): $357-371$

Seckin G (2004) A simple formula for estimating backwater at bridge constrictions. Canadian Journal of Civil Engineering 31(4): $561-568$.

Seckin G (2007) The effect of skewness on bridge backwater prediction. Canadian Journal of Civil Engineering 34(10): 1371-1374.

Seckin G and Atabay S (2005) Experimental backwater analysis around bridge waterways. Canadian Journal of Civil Engineering 32(6): 1015-1029.

Seckin G, Knight DW, Atabay S and Seckin N (2004) Bridge Afflux Experiments in Compound Channels, Phase 2. School of Civil Engineering, University of Birmingham, Birmingham, UK, Report supplied to JBA Consulting.

Seckin G, Knight DW, Atabay S and Seckin N (2008) Improving bridge afflux prediction for overbank flows. Proceedings of the Institution of Civil Engineers - Water Management 161(5): 253-262, https://doi.org/10.1680/wama.2008.161.5.253

Seckin G, Akoz MS, Cobaner M and Haktanir T (2009) Application of ANN techniques for estimating backwater through bridge constrictions in Mississippi river basin. Advances in Engineering Software 40(10): 1039-1046

Sen DJ and Garg NK (1998) Efficient solution technique for dendritic channel networks using FEM. Journal of Hydraulic Engineering 124(8): 831-839.

Sen DJ and Garg NK (2002) Efficient algorithm for gradually varied flows in channel networks. Journal of Irrigation and Drainage Engineering 128(6): 351-357.

Tracy H and Carter R (1955) Backwater effects of open channel constrictions. Transactions of the American Society of Civil Engineers 120: 993-1006.

Zhu D, Chen Y, Wang Z and Liu Z (2011) Simple, robust, and efficient algorithm for gradually varied subcritical flow simulation in general channel networks. Journal of Hydraulic Engineering 137(7): 766-774.

\section{How can you contribute?}

To discuss this paper, please email up to 500 words to the editor at journals@ice.org.uk. Your contribution will be forwarded to the author(s) for a reply and, if considered appropriate by the editorial board, it will be published as discussion in a future issue of the journal.

Proceedings journals rely entirely on contributions from the civil engineering profession (and allied disciplines). Information about how to submit your paper online is available at www.icevirtuallibrary.com/page/authors, where you will also find detailed author guidelines 